\title{
Pitfalls in identifying active catalyst species
}

\author{
Jiazheng $\operatorname{Ren}^{1} \&$ Yongsheng Chen (1) ${ }^{1 凶}$
}

ARISING from Pereira-Hernández, X. I. et al. Nature Communications https://doi.org/10.1038/s41467-019-09308-5 (2019)

C atalytic CO oxidation is an important reaction for both applied and fundamental research. Single-atom catalysts (SACs) have received considerable attention in recent years due to its excellent performance in $\mathrm{CO}$ oxidation. PereiraHernández et al. ${ }^{1}$ prepared Pt SACs using two methods: (1) conventional wet chemical synthesis (strong electrostatic adsorption-SEA) and (2) high-temperature vapor-phase synthesis (atom trapping-AT). As synthesized, both SACs were inactive for low-temperature $\left(<150^{\circ} \mathrm{C}\right) \mathrm{CO}$ oxidation. After a treatment in $\mathrm{CO}$ at $275^{\circ} \mathrm{C}$, both catalysts showed enhanced reactivity. In particular, the AT catalyst was significantly more active, with onset of $\mathrm{CO}$ oxidation near room temperature. The authors claimed that the high reactivity at low temperatures could be related to the improved reducibility of lattice oxygen on the $\mathrm{CeO}_{2}$ support based on nearambient pressure X-ray photoelectron spectroscopy (NAP-XPS) and $\mathrm{CO}$ temperature programmed reduction (CO-TPR). The evidence provided in the paper, when properly analyzed, however, does not support this claim. Specifically, $\mathrm{CO}$ does not react with ceria at $50^{\circ} \mathrm{C}$, and $\mathrm{Pt}$ metal dispersion is significantly higher in the activated AT catalyst than in the SEA, which may well account for the difference in performance between the two catalysts.

The authors intended to use CO-TPR to probe the difference between the two catalysts in the reaction between $\mathrm{CO}$ and oxygen from the catalyst. Experimentally, a catalyst sample would have been "activated via $\mathrm{CO}$ reduction at $275^{\circ} \mathrm{C}$, then exposed to an oxidative atmosphere $\left(10 \% \mathrm{O}_{2}, 30 \mathrm{~min}\right)$ at $200^{\circ} \mathrm{C}$ " before a COTPR test. They stated that "because both catalysts were exposed to an oxidative treatment prior to the CO-TPR, the $\mathrm{CO}_{2}$ must come from reactive oxygen species accessible during reaction", and subsequently claimed that "the AT catalyst contains ceria sites that are reducible at low temperatures where the AT catalyst is active for $\mathrm{CO}$ oxidation". This conclusion is actually directly contradicted by the mass spectrometry results during the NAP-XPS experiments (Supplementary Fig. 11, note all cited Figures in this Comment are referred to those in the original paper ${ }^{1}$ ), which clearly show that at $50{ }^{\circ} \mathrm{C}$, no $\mathrm{CO}_{2}$ was detected for either the AT or the SEA catalyst when only pure $\mathrm{CO}$ was present. In other words, no ceria reduction by $\mathrm{CO}$ at $50^{\circ} \mathrm{C}$ takes place for both catalysts. The most significant difference in the procedures between the CO-TPR and the NAPXPS experiments is the additional oxidative pretreatment in COTPR that the authors had intended "to remove any adsorbed species and to replenish the oxygen on the support". Unfortunately, this oxidative treatment would most likely have re-oxidized the metal Pt to $\mathrm{Pt}$ oxide, which would subsequently contribute to the lowtemperature $\mathrm{CO}_{2}$ signals in CO-TPR. In fact, the NAP-XPS results in Figs. 5 and 6 clearly show reduced contents of $\mathrm{Pt}(0)$ and $\mathrm{Ce}(3+)$ after the catalysts have been treated in $\mathrm{CO}+\mathrm{O}_{2}$ and pure $\mathrm{CO}$ at $50^{\circ} \mathrm{C}$. For example, the $\mathrm{Pt}(0)$ content decreased from 82.7 to $62.0 \%$ for the AT catalyst. The oxidative pretreatment in the CO-TPR experiments employed a more oxidizing atmosphere $\left(30 \% \mathrm{O}_{2}\right)$ and a higher temperature $\left(200^{\circ} \mathrm{C}\right)$ than the conditions used in the NAPXPS experiments. Thus, more Pt oxide is expected to have existed at the beginning of the CO-TPR tests than the extents suggested by the NAP-XPS experiments. Evidently, the low-temperature $\mathrm{CO}_{2}$ signals in the CO-TPR experiment are not from the reduction of the ceria support but more likely from the reduction of Pt oxide introduced by the oxidative treatment in the CO-TPR experiments.

The authors performed NAP-XPS on both catalysts and monitored the change in the composition of $\mathrm{Ce}(3+)$ species. The SEA catalyst had a negligible change in the amount of $\mathrm{Ce}(3+)$ species when exposed to $\mathrm{CO}$ and $\mathrm{CO}$ oxidation cycles while the AT catalyst showed a more noticeable change (see Figs. 5 and 6). The authors claimed that these experiments demonstrated the facile reaction of surface oxygen with $\mathrm{CO}$ adsorbed on the Pt nanoparticles and it helped explain the low-temperature reactivity of the AT catalyst. The inference is again directly contradicted by the mass spectrometry results during the NAP-XPS experiments (Supplementary Fig. 11) as no $\mathrm{CO}_{2}$ was detected when only pure $\mathrm{CO}$ was present. The observed change in the amount of $\mathrm{Ce}(3+)$ species during the $\mathrm{CO}$ and $\mathrm{CO}+\mathrm{O}_{2}$ cycles is probably a direct result of changing $\mathrm{O}_{2}$ partial pressure as $\mathrm{CeO}_{2}$ is a known oxygen storage material and ready to exchange oxygen with the $\mathrm{O}_{2}$ in the surrounding leading to varying Ce chemical state ${ }^{2}$. It may also be a problem with the XPS data analysis. The authors used CasaXPS software to quantify different Ce species with a Shirley background subtraction. The Ce 3d line fitting was carried out according to a model described in two earlier reports in 2009 and $2015^{3,4}$. However, the 2009 report cautioned about Shirley background and further stated that decomposing the complicated spectrum is "partly ambiguous in principle"3. The 2015 report used a linear background ${ }^{5}$, echoing the CasaXPS Manual on Ce data analysis that "a linear background provided the most reproducible results" 5 .

\footnotetext{
${ }^{1}$ Energy and Catalysis Laboratory, Department of Mechanical and Automation Engineering, The Chinese University of Hong Kong, Shatin, New Territories,

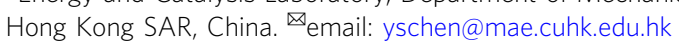


The authors collected HAADF-STEM images for the activated AT and SEA catalysts, found very similar particle size for them, and concluded the differences in reactivity between the AT and SEA catalysts cannot be attributed to the differences in the $\mathrm{Pt}$ particle size and must be related to the catalyst support. However, as reported in the captions of Figs. 5 and 6, the XPS measurements have that the $\mathrm{Pt} / \mathrm{Ce}$ ratios in the activated AT and SEA catalysts were $\sim 0.030$ and $\sim 0.015$, respectively. The significantly higher Pt/Ce ratio in the AT catalyst manifests a better Pt dispersion $^{6}$, which is well known to strongly affect catalysis ${ }^{7}$.

There are other technical issues in the work:

(1) Isothermal $\mathrm{CO}$ oxidation reaction performance at $50{ }^{\circ} \mathrm{C}$ in the NAP-XPS setting over the AT catalyst, as probed by the mass spectrometry (Supplementary Fig. 11), clearly shows that the AT catalyst loses virtually all its activity in about $30 \mathrm{~min}$ (estimated from the $\mathrm{CO}_{2}$ mass profile and the experimental description). Thus, the result undermines the authors' many claims including the benefits of high-temperature vapor-phase synthesis and a suitablefor-industrial-use catalyst with high thermal stability and high activity for low-temperature $\mathrm{CO}$ oxidation. In addition, little performance data have been provided for the AT catalyst. In fact, only 8 data points are shown for the AT catalyst as in Fig. 1, which was a test in $<25 \mathrm{~min}$ (estimated from a starting temperature at $25^{\circ} \mathrm{C}$, the last temperature $<75^{\circ} \mathrm{C}$, and the ramp rate of $2{ }^{\circ} \mathrm{C} / \mathrm{min}$ ). No repeatability/stability data are provided for this catalyst, which are essential for the evaluation of its catalytic performance.

(2) As shown in Fig. 5, the $\operatorname{Pt}(0)$ content evolves from $82.7 \%$, down to $68.0 \%$, further down to $58.9 \%$, and then back up to $62.0 \%$ corresponding to $\mathrm{CO}, \mathrm{CO}+\mathrm{O}_{2}, \mathrm{CO}$, and $\mathrm{CO}+\mathrm{O}_{2}$ atmospheres, respectively. Known chemistry would not be able to explain why there is less $\operatorname{Pt}(0)$ when the atmosphere changes from $\mathrm{CO}+\mathrm{O}_{2}$ to $\mathrm{CO}$ (becoming less oxidizing), and there is more $\mathrm{Pt}(0)$ when it switched back to $\mathrm{CO}+\mathrm{O}_{2}$. Similar result is observed for the SEA catalyst as shown in Fig. 6. Moreover, the authors performed a harsh reduction treatment with $\mathrm{CO}$ at $450{ }^{\circ} \mathrm{C}$ for $8 \mathrm{~h}$ to probe the strength of the interaction between $\mathrm{Pt}$ and $\mathrm{CeO}_{2}$ (Supplementary Fig. $10 \mathrm{c}, \mathrm{d})$. For the AT catalyst, $94.5 \% \mathrm{Pt}$ was reduced to $\mathrm{Pt}(0)$ while $18.9 \%$ Ce reduced to $\mathrm{Ce}(3+)$; Fig. 5 shows a milder reduction treatment of the same catalyst resulting in a plausible $82.7 \%$ of $\mathrm{Pt}(0)$ and a troubling $28.1 \%$ of $\mathrm{Ce}(3+)$. These may again be a problem with the XPS data analysis as discussed earlier. The authors should process their XPS data using a linear background, which hopefully would result in consistent other than self-contradicting results.

(3) $\mathrm{CO}$ oxidation reaction was monitored by DRIFTS on the activated AT and SEA catalysts at $50{ }^{\circ} \mathrm{C}$ (see Fig. 3c, d). More gas phase $\mathrm{CO}_{2}$ is recorded for the SEA catalyst than the AT catalyst. This is in direct contradiction to the activity measurements that the AT catalyst is active at this temperature while the SEA is not.

(4) Calculation of the turnover frequency (TOF). The authors had it right when stating "The TOF was calculated using the number of $\mathrm{CO}_{2}$ molecules formed per second (rate) divided by the number of active sites". However, it is not selfconsistent when the active sites were calculated by using the total number of $\mathrm{Pt}$ atoms deposited on the ceria surface. On one hand, if the authors truly believe that some ceria sites are determining the low-temperature activity of the AT catalyst, then it would be more logical to use the number of "active ceria sites" in the calculation. On the other hand, if the authors believe the surface metal Pt sites are active as shown in Fig. 7, it is clear that "the total number of $\mathrm{Pt}$ atoms deposited on the ceria surface" would not be the right count because it includes single-atom Pt species and inaccessible metal $\mathrm{Pt}$ atoms in the bulk.

\section{Data availability}

The data cited in the current work are all from Pereira-Hernández, X. I. et al.'s work and available at https://doi.org/10.1038/s41467-019-09308-5.

Received: 17 February 2020; Accepted: 22 July 2020;

Published online: 11 September 2020

\section{References}

1. Pereira-Hernández, X. I. et al. Tuning $\mathrm{Pt}-\mathrm{CeO}_{2}$ interactions by hightemperature vapor-phase synthesis for improved reducibility of lattice oxygen Nat. Commun. 10, 1358 (2019).

2. Grinter, D. C. et al. Spillover reoxidation of ceria nanoparticles. J. Phys. Chem. C. 120, 11037-11044 (2016).

3. Skála, T., Šutarabc, F., Prince, K. C. \& Matolín, V. Cerium oxide stoichiometry alteration via Sn deposition: Influence of temperature. J. Electron Spectrosc. 169, 20-25 (2009)

4. Kato, S. et al. Quantitative depth profiling of $\mathrm{Ce}^{3+}$ in $\mathrm{Pt} / \mathrm{CeO}_{2}$ by in situ high energy XPS in a hydrogen atmosphere. Phys. Chem. Chem. Phys. 17, 5078-5083 (2015)

5. Fairley, N. CasaXPS Manual 2.3. 15. (Casa Software Ltd, Teignmouth, 2009).

6. Niemantsverdriet, J. W. Spectroscopy in Catalysis: An Introduction. (John Wiley \& Sons, Hoboken, 2007).

7. Imelik, B. Metal-Support and Metal-Additive Effects in Catalysis. (Elsevier, Amsterdam, 1982).

\section{Author contributions}

Y.C. reinterpreted the experimental results in the concerned publication. J.R. and Y.C. wrote the paper.

\section{Competing interests}

The authors declare no competing interests.

\section{Additional information}

Correspondence and requests for materials should be addressed to Y.C.

Peer review information Nature Communications thanks the anonymous reviewer(s) for their contribution to the peer review of this work.

Reprints and permission information is available at http://www.nature.com/reprints

Publisher's note Springer Nature remains neutral with regard to jurisdictional claims in published maps and institutional affiliations.

Open Access This article is licensed under a Creative Commons Attribution 4.0 International License, which permits use, sharing, Ay Attribution 4.0 International License, which permits use, sharing,
adaptation, distribution and reproduction in any medium or format, as long as you give appropriate credit to the original author(s) and the source, provide a link to the Creative Commons license, and indicate if changes were made. The images or other third party material in this article are included in the article's Creative Commons license, unless indicated otherwise in a credit line to the material. If material is not included in the article's Creative Commons license and your intended use is not permitted by statutory regulation or exceeds the permitted use, you will need to obtain permission directly from the copyright holder. To view a copy of this license, visit http://creativecommons.org/ licenses/by/4.0/

(c) The Author(s) 2020 